\title{
Tuning Cell Differentiation into a 3D Scaffold Presenting a Pore Shape Gradient for Osteochondral Regeneration
}

Citation for published version (APA):

Di Luca, A., Lorenzo-Moldero, I., Mota, C., Lepedda, A., Auhl, D., Van Blitterswijk, C., \& Moroni, L. (2016). Tuning Cell Differentiation into a 3D Scaffold Presenting a Pore Shape Gradient for Osteochondral Regeneration. Advanced Healthcare Materials, 5(14), 1753-1763. https://doi.org/10.1002/adhm.201600083

Document status and date:

Published: 20/07/2016

DOI:

10.1002/adhm.201600083

Document Version:

Publisher's PDF, also known as Version of record

Document license:

Taverne

Please check the document version of this publication:

- A submitted manuscript is the version of the article upon submission and before peer-review. There can be important differences between the submitted version and the official published version of record.

People interested in the research are advised to contact the author for the final version of the publication, or visit the DOI to the publisher's website.

- The final author version and the galley proof are versions of the publication after peer review.

- The final published version features the final layout of the paper including the volume, issue and page numbers.

Link to publication

\footnotetext{
General rights rights.

- You may freely distribute the URL identifying the publication in the public portal. please follow below link for the End User Agreement:

www.umlib.nl/taverne-license

Take down policy

If you believe that this document breaches copyright please contact us at:

repository@maastrichtuniversity.nl

providing details and we will investigate your claim.
}

Copyright and moral rights for the publications made accessible in the public portal are retained by the authors and/or other copyright owners and it is a condition of accessing publications that users recognise and abide by the legal requirements associated with these

- Users may download and print one copy of any publication from the public portal for the purpose of private study or research.

- You may not further distribute the material or use it for any profit-making activity or commercial gain

If the publication is distributed under the terms of Article $25 \mathrm{fa}$ of the Dutch Copyright Act, indicated by the "Taverne" license above, 


\title{
Tuning Cell Differentiation into a 3D Scaffold Presenting a Pore Shape Gradient for Osteochondral Regeneration
}

\author{
Andrea Di Luca, Ivan Lorenzo-Moldero, Carlos Mota, Antonio Lepedda, Dietmar Auhl, \\ Clemens Van Blitterswijk, and Lorenzo Moroni*
}

Osteochondral regeneration remains nowadays a major problem since the outcome of current techniques is not satisfactory in terms of functional tissue formation and development. A possible solution is the combination of human mesenchymal stem cells (hMSCs) with additive manufacturing technologies to fabricate scaffolds with instructive properties. In this study, the differentiation of hMSCs within a scaffold presenting a gradient in pore shape is presented. The variation in pore shape is determined by varying the angle formed by the fibers of two consequent layers. The fiber deposition patterns are 0-90, which generate squared pores, $0-45,0-30$, and $0-15$, that generate rhomboidal pores with an increasing major axis as the deposition angle decreases. Within the gradient construct, squared pores support a better chondrogenic differentiation whereas cells residing in the rhomboidal pores display a better osteogenic differentiation. When cultured under osteochondral conditions the trend in both osteogenic and chondrogenic markers is maintained. Engineering the pore shape, thus creating axial gradients in structural properties, seems to be an instructive strategy to fabricate functional 3D scaffolds that are able to influence hMSCs differentiation for osteochondral tissue regeneration.

by combining engineer fundamentals and biological factors. ${ }^{[1]}$ In the past couple of decades stem cells gathered the attention of the scientific community due to their ability to differentiate into multiple lineages. ${ }^{[2,3]}$ Human mesenchymal stromal or stem cells (hMSCs) can differentiate into osteoblasts, chondrocytes, and adipocytes, among other cell types, their use does not raise the same ethical concerns of embryonic stem cells ${ }^{[2]}$ and are safer in terms of potential tumor formation. Furthermore, when used in combination with biomaterials, one could think of designing 3D scaffolds with instructive properties that can harness hMSCs differentiation potential directly at the site of implantation.

Several environmental cues influence hMSCs differentiation, such as oxygen and nutrient availability, ${ }^{[4,5]}$ substrate characteristics such as physicochemical and mechanical properties, ${ }^{[6,7]}$ porosity and pore geometry, ${ }^{[8-10]}$ and the addition of soluble factors. ${ }^{[2]}$

\section{Introduction}

Severe injuries in the human body result in a healing process that leads to scar formation and a loss of function of the injured area. The purpose of tissue regeneration is to repair the targeted tissue restoring the function of the injured site,

\footnotetext{
A. Di Luca, Prof. C. A. Van Blitterswijk, Prof. L. Moroni Tissue Regeneration Department

University of Twente

Drienerlolaan 5, 7522 NB, Enschede, The Netherlands

E-mail: I.moroni@maastrichtuniversity.nl

Dr. I. Lorenzo-Moldero, Dr. C. Mota,

Prof. C. A. Van Blitterswijk, Prof. L. Moroni

Complex Tissue Regeneration Department

MERLN Institute for Technology Inspired Regenerative Medicine

Maastricht University

6229 ER, Maastricht, The Netherlands

Dr. A. Lepedda

Department of Biomedical Sciences

University of Sassari

via Muroni 25, Italy

Dr. D. Auhl

AMIBM Aachen-Maastricht Institute for Biobased Materials

Maastricht University

PO Box 616, 6200 MD, Maastricht, The Netherlands

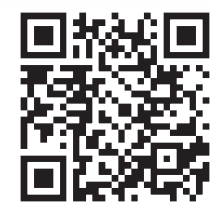

DOI: 10.1002/adhm.201600083
In their natural state, cells grow and solve their function in a 3D environment. For tissue regeneration purposes, many strategies have been applied to generate 3D structures providing a macroscopic environment that allows to lodge cells and let them produce the required proteins forming tissue extracellular matrix (ECM). Among others, salt leaching, solvent casting, and gas foaming have been extensively used in the past decades. ${ }^{[11,12]}$ The major limitation of these techniques is the impossibility to tune the size, interconnectivity, and geometry of the pore structure, hence impeding the perfusion of the inner part of the construct by nutrients and the migration of cells within the scaffold. A set of possible tools that enables to overcome this problem consists of additive manufacturing (AM) technologies, emerged in the regenerative medicine field in the past years due to the possibility of tuning structural parameters like the diameter, distance, and orientation of the struts comprising the final 3D scaffolds. By doing this in a layer-by-layer manner, the resulting scaffolds have fully interconnected pore structures with tunable pore size and shape. ${ }^{[10]}$

Gradients are present all over the body, leading a number of events and processes in the embryonic as well as in the adult stage of life. For example, processes such as the development of osteochondral, tendon, and ligament tissues are governed by morphogens and oxygen gradients. ${ }^{[13]}$ Structural gradients can be found in the body mainly at the interface between tissues. The osteochondral tissue, in particular, represents an interesting biological interface to take into consideration, both 
from a biological and a clinical point of view. From the subchondral bone side of the osteochondral tissue, the ECM passes from a mineralized collagen type I to a less mineralized collagen type $\mathrm{X}$ and a nonmineralized collagen type II in the deep zone of the articular cartilage. This variation in ECM composition continues throughout the entire articular cartilage tissue with an increase in collagen type II content and a parallel decrease of glycosaminoglycans (GAGs) from the deep to the superficial zone. Mechanical properties and nutrient availability follow a similar trend. ${ }^{[14]}$ Biologically, the mechanism at the base of stem cell driven osteochondral differentiation is not fully dissected. It is known that the presence of certain soluble factors is able to start hMSCs differentiation toward the osteogenic (dexamethasone, BMP-2 $)^{[15,16]}$ or the chondrogenic lineage (insulin, TGF- $\beta 1$ and TGF- $\beta 3) \cdot{ }^{[17,18]}$ The regeneration of the osteochondral tissue requires, therefore, 3D scaffolds that are able to present the right cues in a spatially defined way. Clinically, current therapies to regenerate the osteochondral tissue are not yet completely successful. All the currently available treatments such as reparative surgery, allografts, autografts, and the implantation/ transplantation of autologous chondrocytes inflict further tissue destruction in other healthy tissue sites before any therapeutic effect can be achieved. Furthermore, some of these clinical treatments are additionally limited to the availability of donor supply and lead to the formation of fibrocartilage, thus not restoring the proper function of hyaline cartilage. ${ }^{[19,20]}$

Among all the cues influencing cell behavior, scaffold's pore geometry and shape is known to play an important role. Pore geometry is known to have an effect on tissue growth within a pore in vitro and in vivo. ${ }^{[21,22]}$ The study of Berner et al. showed increased cranial bone healing and mechanical properties when the fiber's laydown pattern was $0^{\circ} / 90^{\circ}$ with respect to $0^{\circ} / 60^{\circ} / 120^{\circ}{ }^{\left[{ }^{[22]}\right.}$ Bidan et al. showed that when the MC-3T3 preosteoblasts were seeded into scaffolds displaying squared and cross-shaped pores, a different profile of ECM deposition could be observed, with an initial ECM deposition increased in cross shaped pores. ${ }^{[21]}$ Hence, the design of scaffolds with structural gradients such as pore shape may stimulate the differentiation of hMSCs and lead to improved tissue regeneration strategies.

The concept of gradient has been applied already in different studies in 2D and 3D. ${ }^{[23-30]}$ The work of Woodfield and Sobral displayed an improved cell seeding efficiency on AM scaffolds presenting a pore-size gradient for already differentiated cells such as bovine chondrocytes and human osteosarcoma cells (SaOs-2), respectively. ${ }^{[10,31]}$ Yet, no study focused on the effect of scaffolds' structural gradients on the differentiation of hMSCs. Here, we present 3D scaffolds with a gradient in pore shape and we analyze the influence of such structural gradients on seeded hMSCs activity for osteochondral tissue regeneration. We further dissect the structural gradient in order to highlight the differences in behavior among the compartment of the construct based on changes in pore shape.

\section{Results}

\subsection{Construct Analysis}

A gradient structure was plotted by varying the fiber deposition pattern along the $\mathrm{Z}$ axis. The resulting fiber diameter and fiber height were not affected by the angle deposition, being $150 \mu \mathrm{m} \pm 20 \mu \mathrm{m}$ and $140 \mu \mathrm{m} \pm 20 \mu \mathrm{m}$, respectively. On the other hand the fiber spacing varied from one gradient region to another. Squared pores displayed a fiber spacing of $510 \mu \mathrm{m} \pm$ $30 \mu \mathrm{m}, 0-45$ deposition pattern showed a fiber spacing of $490 \mu \mathrm{m}$ $\pm 40 \mu \mathrm{m}, 0-30$ and $0-15$ had a fiber spacing of $530 \mu \mathrm{m} \pm 20 \mu \mathrm{m}$ and $480 \mu \mathrm{m} \pm 20 \mu \mathrm{m}$, respectively. As shown in Table 1, the change of the fiber deposition pattern resulted in a variation of the pore shape and size whereas the porosity was not affected. The 0-90 configuration determined squared pores and a porosity of $74 \% \pm 3 \%$, which became rhomboidal with a porosity of $72 \% \pm 5 \%$ by varying the deposition pattern to $0-45$. The further decrease in angle deposition resulted in stretching the rhomboidal pores with an increase of the major diagonal and a parallel decrease of the minor diagonal. The fiber deposition pattern $0-30$ and $0-15$ showed a porosity of $75 \% \pm 7 \%$ and $73 \% \pm 6 \%$, respectively. Besides the variation in pore shape all the pore features (perimeter, area, and volume) changed along the gradient direction with a minor difference between $0-90$ and $0-45$ angle depositions and a marked one among 0-45, 0-30, and $0-15$ angle depositions. Scaffolds with constant pore geometry $(0-90$ and $0-15)$ were plotted and used as controls. The scaffolds were cylindrical in shape with a diameter of $6 \mathrm{~mm}$ and a height of $3.6 \mathrm{~mm}$. The porosity of the gradient (G) scaffolds was $74 \% \pm 5 \%$, while $0-90$ nongradient (NG90) and 0-15 nongradient (NG15) scaffolds showed a porosity of $74 \% \pm 3 \%$ and $73 \%$ $\pm 6 \%$, respectively. Mechanical properties analysis (Figure 1) indicated that $\mathrm{G}$ scaffolds have a stiffer response to compression for a force range of $1 \mathrm{~N}$ compared to NG90 and NG15 scaffolds, respectively. The recovery of gradient scaffolds appeared less prone to hysteresis effects compared to nongradient scaffolds. However, for a force range between $5 \mathrm{~N}$ and $10 \mathrm{~N}$, the loading and unloading response became similar (Figure 1b). The total deformations upon compression were in the range of $2 \%-6 \%$ of height reduction, thus well within the elastic region.

\subsection{Cell Seeding, Growth, and ECM Deposition}

Cell seeding efficiency was not significantly affected by the geometry of the construct (Figure S1, Supporting Information). The NG15 scaffolds showed a lower cell adhesion, about $60 \%$, in the first $8 \mathrm{~h}$. The gradient and the NG90 scaffolds showed a cell seeding efficiency of about $75 \%-80 \%$. The direction of the gradient did not affect cell attachment after $8 \mathrm{~h}$ (Figure S1, Supporting Information). For the rest of the study, the chosen gradient direction during the seeding was maintained with squared pores at the bottom and rhomboidal on top of the scaffolds.

Cell number increased in the first week under proliferation conditions and kept increasing also in the first week of differentiation. During the following 3 weeks of differentiation, the cell number decreased in the first week and remained stable for the last 2 weeks of culture (Figure 2). Under osteogenic and chondrogenic conditions the cell number maintained the same trend (Figure S2, Supporting Information).

Despite the absence of differences in cell number, after 35 days of culture (7 days in proliferation medium followed by 28 days in basic, osteogenic, or chondrogenic medium) the gradient constructs showed an increased ECM production 
Table 1. The variation in pore size determined an increase in pore perimeter, area, and volume from squares to rhomboids without significantly affecting the porosity.

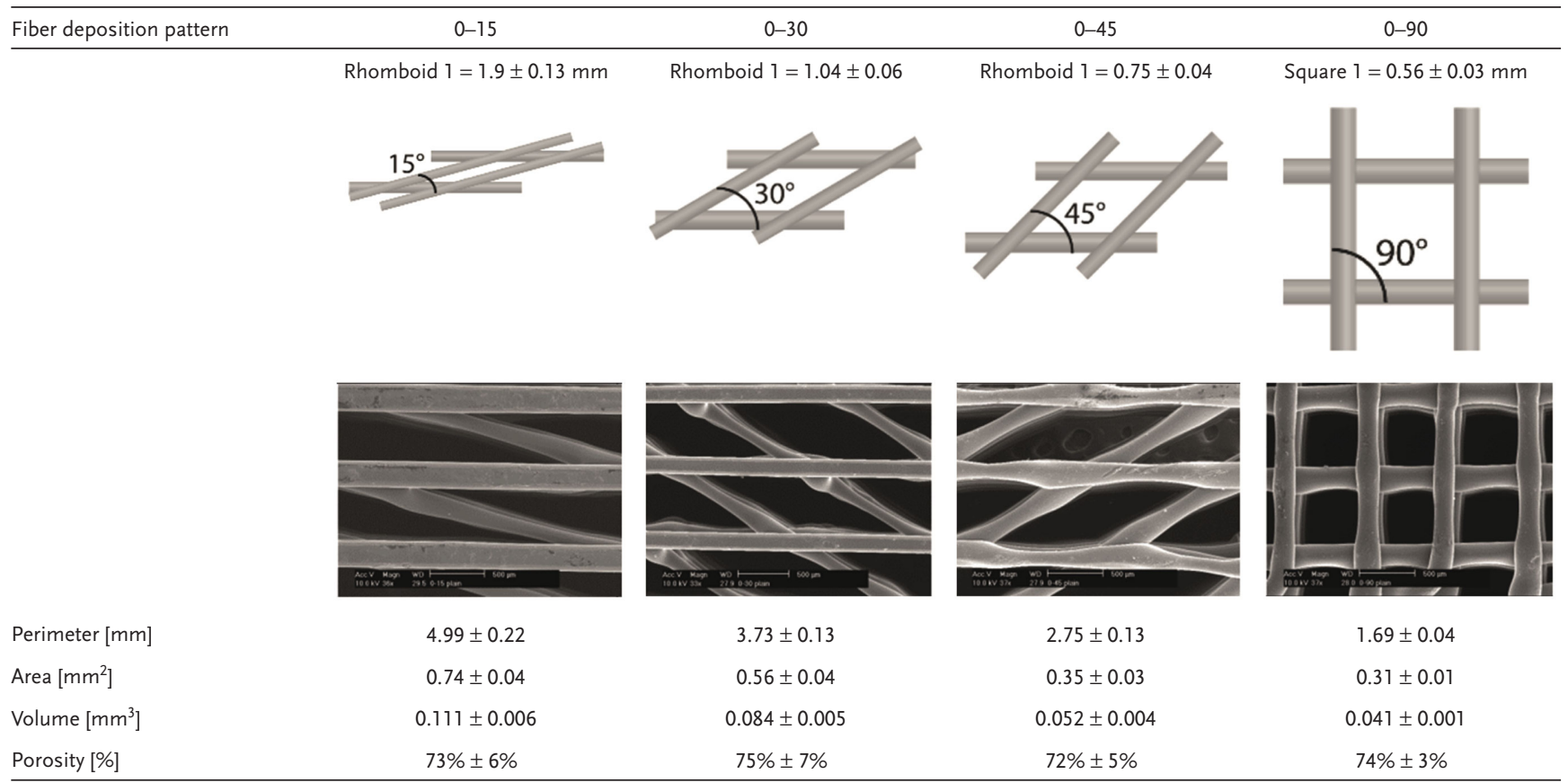

compared to the controls (Figure 3a), with a more rounded cell morphology on the $0-90$ areas compared to the $0-15$ regions (Figure S3, Supporting Information). In NG15 and NG90 scaffolds, cells mainly wrapped the fibers (Figure $3 e, f$ ) and in some cases bridged some fibers in NG90 (Figure 3e,h). In the gradient construct the ECM was not only bridging the fibers but filling the pores as well (Figure 3a,d,g)

\section{3. hMSCs Differentiation}

Under chondrogenic conditions the structural pore shape gradient of the scaffolds was correlated with an enhanced expression of chondrogenesis related genes after 14 days (Figure 4a). Aggrecan and collagen II alpha were four to five times higher compared to the controls, whereas Sox-9 displayed a threefold increase with respect to NG15. In terms of biochemical analysis, no major differences could be seen for GAGs synthesis among the groups at the same time point, even though there was a significant increase of GAGs production during culture under chondrogenic conditions (Figure 5a). Collagen type II production was also increased in $\mathrm{G}$ scaffolds after 2 weeks (Figure S5, Supporting Information). Under basic conditions, as expected, the increase in GAG amount was less pronounced. During the first 2 weeks, GAGs production increased significantly, while in the last 2 weeks it remained constant.
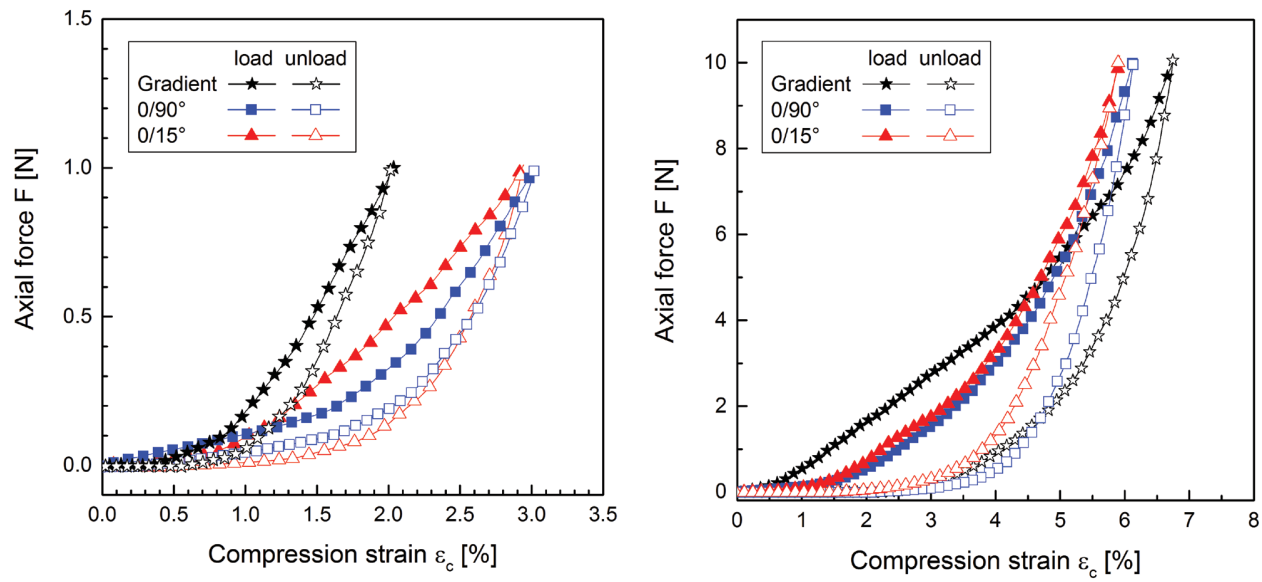

Figure 1. Mechanical response of gradient and nongradient $\left(0 / 15^{\circ}\right.$ and $\left.0 / 90^{\circ}\right)$ scaffolds to axial compression load and unload with $1 \mu \mathrm{m} \mathrm{s} \mathrm{s}^{-1}$ in the axial z-direction at $37^{\circ} \mathrm{C}$ up to (left) $1 \mathrm{~N}$ and (right) $10 \mathrm{~N}$. 


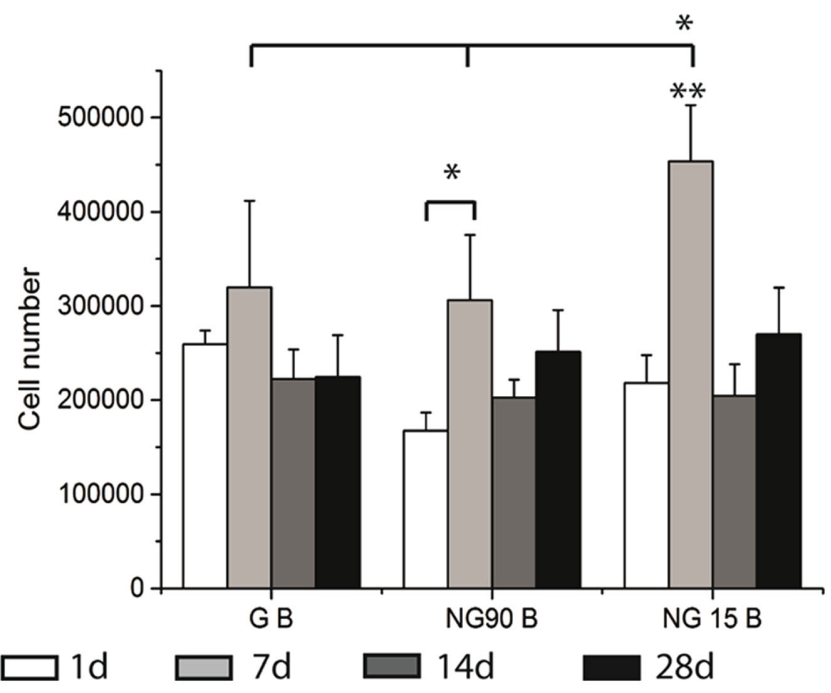

Figure 2. Cell number over time in the constructs cultured in basic medium. The same trend was shown by all the constructs over time. No major differences could be seen among the scaffolds at the same time point, with the exception of NG15B at $7 \mathrm{~d}$ that was significantly higher in respect to the other conditions and time points. * Statistical significance $p<0.05 ; * *<0.01$.

Under osteogenic conditions no major differences could be seen among osteogenesis related genes for the different constructs, with the exception of BMP-2 which was significantly increased in G scaffolds compared to NG15 and NG90 scaffolds (Figure $4 \mathrm{~b}$ and Figure S4, Supporting Information). Bone sialoprotein seemed to be significantly enhanced in NG90 with respect to NG15. The alkaline phosphatase (ALP) activity did not show any significant difference among the gradient scaffolds and controls at any time point (Figure 5b). Osteocalcin production was increased in NG15 and G scaffolds compared to NG90 scaffolds (Figure S5, Supporting Information). hMSCs cultured in basic medium displayed an increase in ALP activity in the first 7 days followed by a decrease during the rest of the study.

\section{4. hMSCs Differentiation within the Gradient Zones}

To better understand if any difference is present among the cells residing in the different gradient zones, a partition analysis was performed after 14 and 28 days of differentiation, followed by gene expression analysis and biochemical analysis, respectively. Chondrogenic markers displayed a significant difference among the rhomboidal region and the squared pore region, in which the genes were overexpressed (Figure 6a). The same trend was shown by the biochemical analysis in terms of GAGs synthesis (Figure 7a). The amount of GAG deposited was normalized by the cell density intended as DNA amount per pore volume (Figure S6a, Supporting Information) and by the pore volume only (Figure S6b, Supporting Information). The trend remained unvaried also when the pore volume was considered in the analysis, thus suggesting that the observed enhanced differentiation is dependent only on the pore shape. Under osteogenic conditions an opposite trend with respect to the chondrogenic one could be observed, in which the rhomboidal
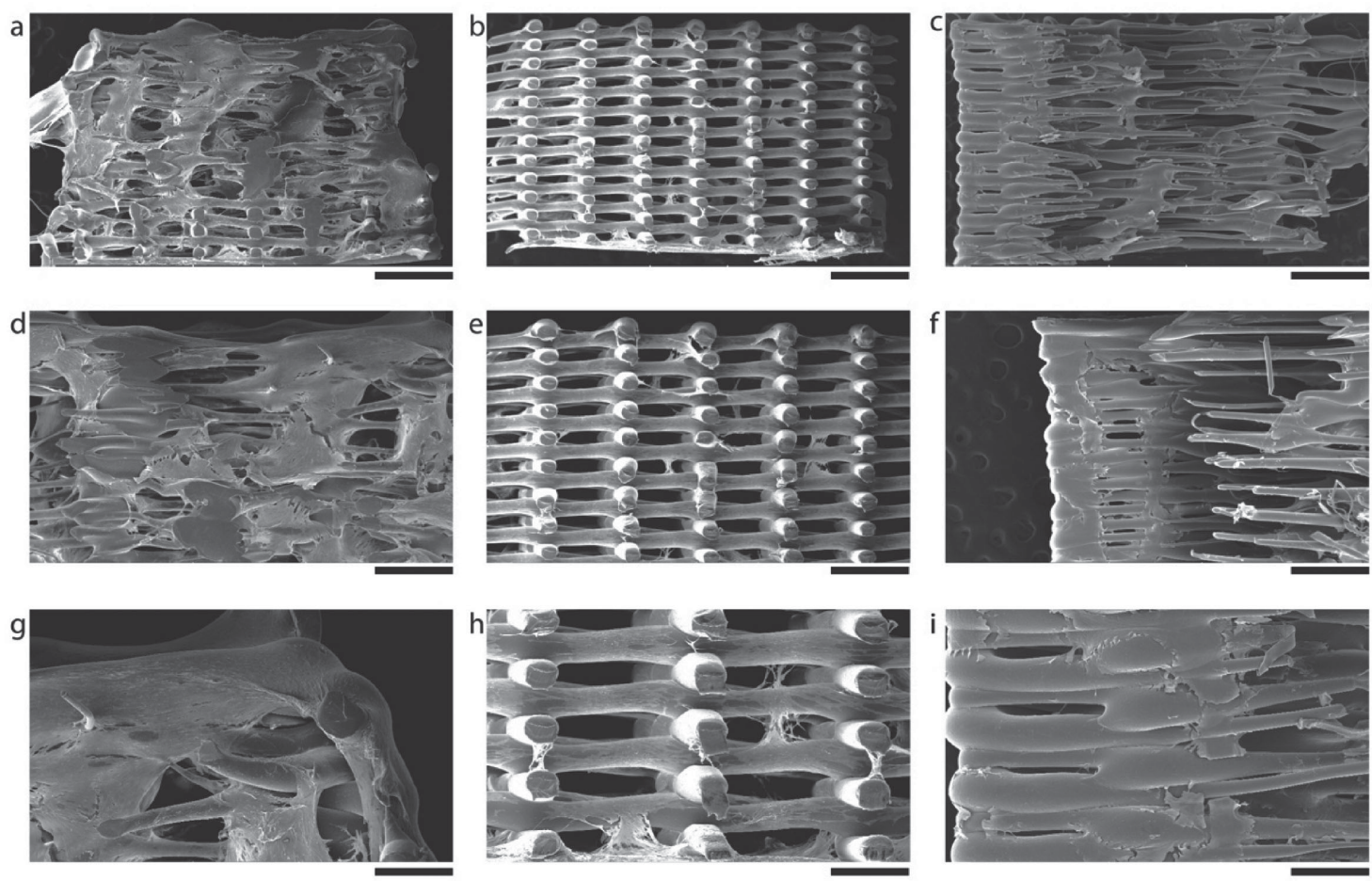

Figure 3. ECM production at day 28 in basic medium. A full view and close-up of (a,d,g) G, (b,e,h) NG 90, and (c,f,i) NG 15 scaffolds, respectively, is displayed at increasing magnifications. Despite the absence of differences in cell number after 28 days of differentiation, the gradient constructs showed an increased ECM deposition, probably due to an increased number of fiber contact points. Scale bar: (a-f) $1 \mathrm{~mm}$ and $(\mathrm{g}-\mathrm{i}) 500 \mu \mathrm{m}$. 

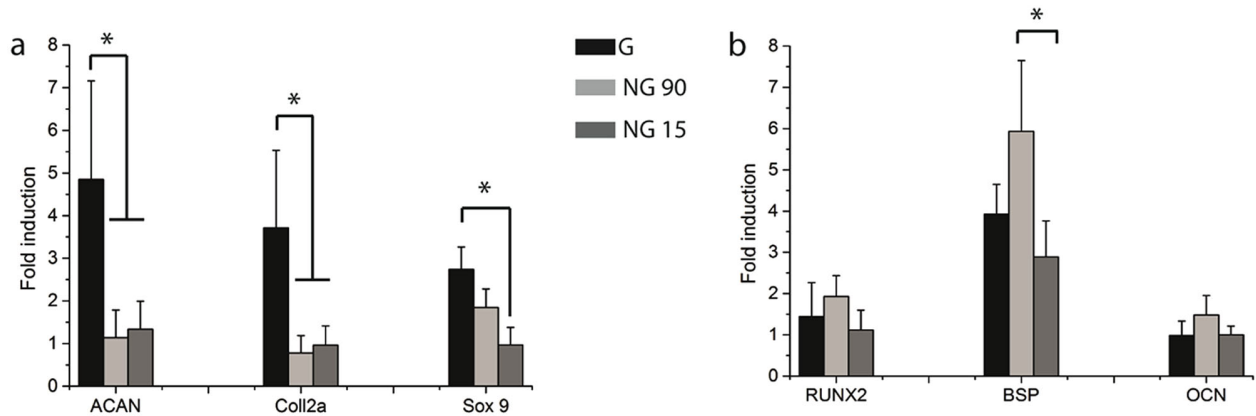

Figure 4. Fold increase of (a) chondrogenic and (b) osteogenic markers under chondrogenic and osteogenic conditions, respectively. Under chondrogenic conditions the gradient greatly enhanced the expression of chondrogenic markers in comparison to the controls. Under osteogenic conditions the NG90 scaffolds enhanced the expression of BSP after $14 \mathrm{~d}$. The fold induction was normalized by the gene expression of hMSCs cultured in gradient scaffolds in basic medium. $* p<0.05$.

a

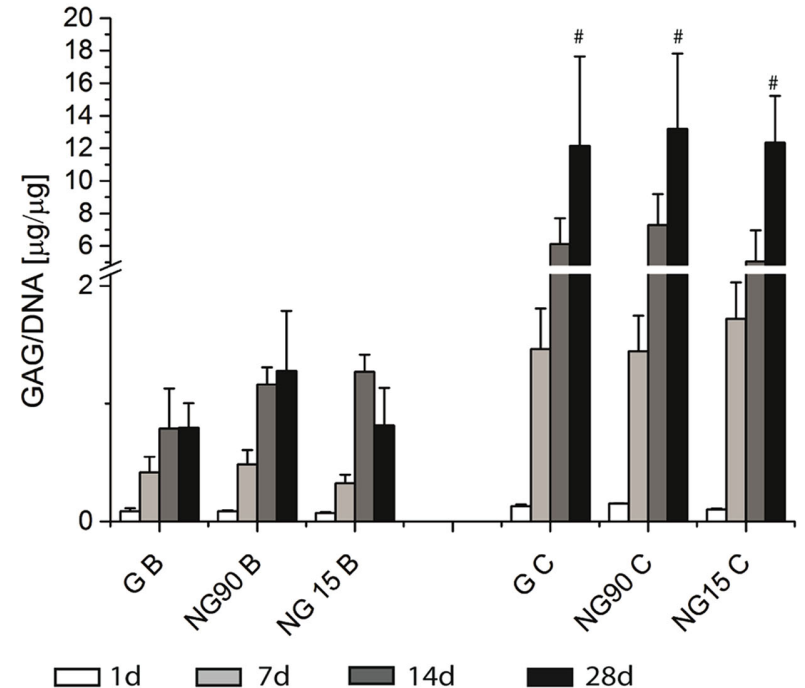

b

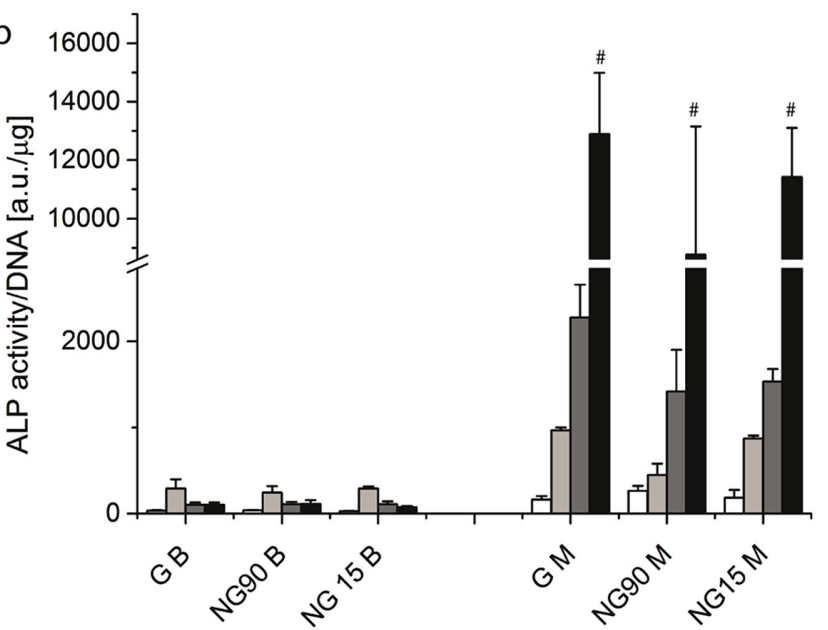

Figure 5. (a) GAGs amount over time normalized by DNA amount and (b) ALP activity over time normalized by DNA amount. Under chondrogenic conditions an increase in GAGs was detected, even though no significant differences could be seen among the constructs within the same time point. Similarly, under mineralization conditions the ALP activity increased over time without significant differences among the $G$ and the NG scaffolds. \# shows statistical significance with respect to previous time points, $p<0.05$.

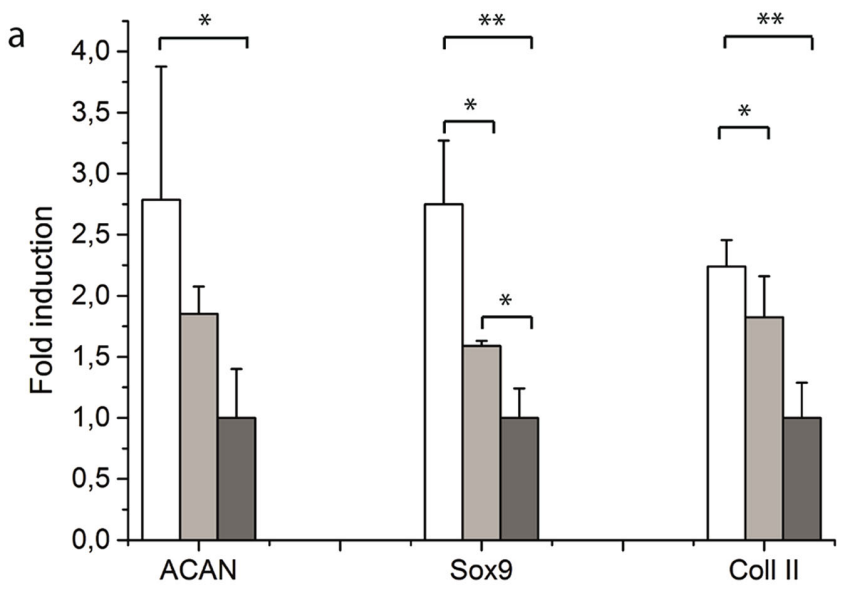

$0-90$

$0-45$

$0-30 / 0-15$

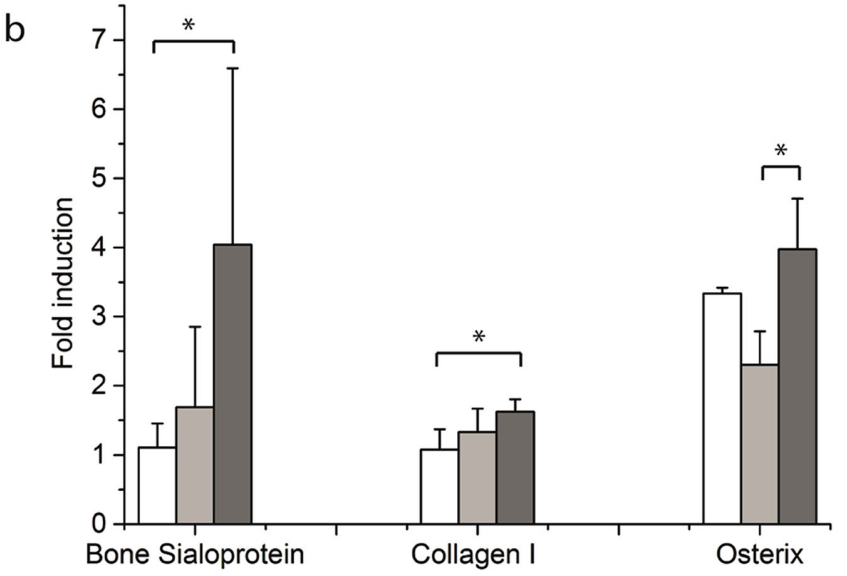

Figure 6. Fold increase of (a) chondrogenic and (b) osteogenic markers under chondrogenic and osteogenic conditions, respectively, after 28 days in the different gradient zones. Under chondrogenic conditions the squared shape gradient greatly enhanced the expression of chondrogenic markers. Under osteogenic conditions the trend was inverted. * Statistical significance with respect to the rhomboidal squared area, $p<0.05 ; * * p<0.01$. 

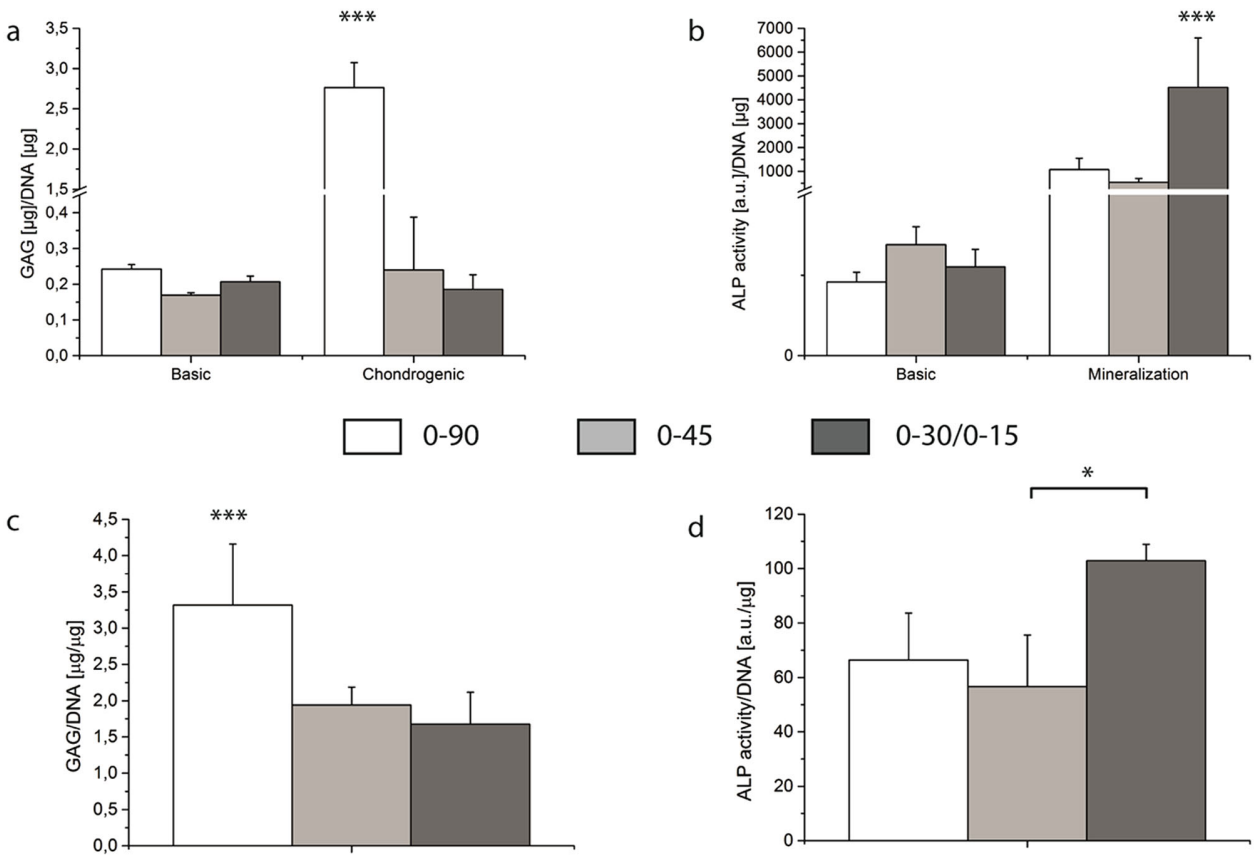

$0-45$
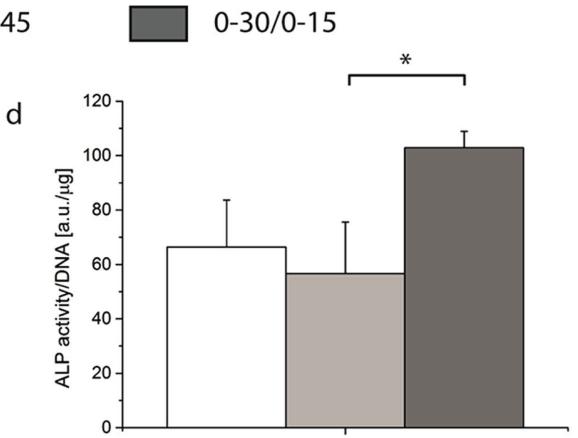

Figure 7. After 28 days, (b) the ALP activity was significantly increased by the rhomboidal geometry whereas (a) GAC deposition was greater in the squared pore area. (c) GAGs and (d) ALP analysis of gradient scaffolds cultured under osteochondral conditions. Briefly, the hMSCs within the scaffolds were cultured in a medium composed by chondrogenic and osteogenic medium in a 1:1 ratio. The opposite trend in differentiation was maintained. The rhomboidal pores supported a better ALP activity while the squared pores displayed a higher GAC deposition. * Statistical significance with respect to the rhomboidal squared area, $p<0.05 ; * * * p<0.001$

shapes enhanced the expression of osteogenic differentiation related genes (Figure 6b). Also ALP activity (Figure 7b) was significantly higher in the rhomboidal pores $(0-30 / 15)$ with respect to the other zones.

The culture of gradient structures in medium containing both osteogenic and chondrogenic soluble signals resulted in an increase of GAGs deposition (Figure 7c) in the squared pore region (0-90) and of ALP (Figure 7d) activity in the rhomboidal pore (0-30/0-15) shaped zone, thus confirming the results obtained in single differentiation medium. As displayed in Figure S7a,b (Supporting Information), the trend did not vary when the structural component was considered for chondrogenic analysis. A possible reason for the observed trends could be due to the local variations in nutrients availability, in particular oxygen, which could result in different degree of hypoxia in the gradient scaffolds regions. To test this hypothesis, hypoxia inducible factor (HIF)- $1 \alpha$ and HIF- $2 \alpha$ were measured (Figure S8, Supporting Information), showing an increased expression in the more chondrogenic squared pore region.

\section{Discussion}

In this study, we presented a novel strategy to generate a structural gradient in pore size and shape in 3D scaffolds fabricated by $\mathrm{AM}$, in which the fiber deposition pattern was changed every $0.9 \mathrm{~mm}$. The conventional plotting setting $0-a$ is determined by " 0 " as the starting direction of the layer and " $a$ " as the increase in the angle between the fibers of one layer and the subsequent one. ${ }^{[12,22]}$ Conventional plotting has led so far mainly to squared pores in the 0-90 pattern and honeycomb like pore shape in the other patterns, in which pores are defined by several fibers from different layers. ${ }^{[32]}$ In this study, the pattern $0-a-0-a$ was used (for example 0-45-0-45) in order to have a pore defined by two subsequent layers and have a constant pore shape for six layers $(0.9 \mathrm{~mm})$. The variation in fiber deposition pattern determined a variation in the pore geometry and size, where decreasing the angle of deposition resulted in an increased rhomboidal shape and a consequent increase in pore perimeter, area, and volume. The increase was not continuous, since it was a discrete gradient in which four zones could be identified, whereas the control scaffolds showed the same pore geometry and size along the longitudinal axis. The scaffolds were made by poly( $\varepsilon$-caprolactone) (PCL), since this material was already applied in surgery and clinical trials are currently ongoing. ${ }^{[33,34]}$ When considering the mechanical analysis of the fabricated scaffolds, different deformations or slopes between the loading and unloading phases highlighted the characteristic damping effects at corresponding response times. Different reductions in the stiffness compared to a solid cylinder arise from the complex order and geometry of the AM scaffolds. Thus, the angle variations in the layer deposition led to variations in the mechanical response, which is dominated by the interactions of individual strands within the regular ordered shapes of the scaffolds. The mechanical behavior can be understood and explained from structural mechanics, where the layer dimensions and directions have to be taken into account.

In literature, improved cells seeding efficiency in plotted scaffold showing a gradient in porosity has been already reported. ${ }^{[31]}$ In our constructs no major differences could be 
seen among the samples in which the cell seeding efficiency was within the $60 \%-80 \%$ range. Even though the cell number profile was the same in the gradient constructs and controls, enhanced ECM deposition could be seen in gradient scaffolds. The geometry seemed not to affect the cell number after seeding or the hMSCs proliferation trend (Figure 2). In control scaffolds cells covered the fibers and in the 0-90 configuration bridged the fibers through the pores, whereas in gradient scaffolds ECM was present all over the structure independently from the pore geometry. Bidan et al. observed different pore closure patterns of scaffolds seeded with MC3T3-E1 preosteoblasts depending on the pore geometry. Pore closure began at the edges and moved toward the center of the pore; ${ }^{[21]}$ in this study, the increased number of fiber connections of the gradient scaffolds might have brought to a faster and higher pore closure with respect to the controls, probably due to an increased number of fiber connections where the pore closure could begin.

Several scaffolds based on PLGA microspheres were studied, which presented a gradient in order to promote hMSCs differentiation (i.e., stiffness and growth factors) $)^{[30,35,36]}$; the solely pore geometry was never studied as a cue supporting hMSCs differentiation. After 14 days of culture, we showed that the chondrogenic markers aggrecan, sox 9 and collagen $\operatorname{II} \alpha$ were significantly upregulated with respect to the nongradient scaffolds. Despite a continuous increase in GAGs amount in all the scaffolds tested with culture time, evidencing the correct chondrogenic differentiation of hMSCs in the presence of soluble factors, differences among gradient and nongradient scaffolds were not visible at a bulk biochemical level when measuring GAGs deposition.

No major differences were shown by hMSCs growing in gradient or nongradient scaffolds in relation to early gene osteogenic markers such as runx2 and late markers such as osteocalcin after 14 days. Also at the protein level no major differences were shown between the ALP activity of cells cultured in G and NG scaffolds. According to Yilgor et al., a link between the geometry of the construct and the osteogenic differentiation of hMSCs might be established and the scaffold geometry could be optimized to improve hMSCs osteogenic differentiation. ${ }^{[37]}$ Our findings are in line with this hypothesis. In Yilgor's study, PCL scaffolds made with different architectures were analyzed. It was shown that the 0-90 conformation with an offset of $380 \mu \mathrm{m} \pm 20 \mu \mathrm{m}$ (the size of 1 fiber) displayed the highest ALP levels compared to other scaffolds with 0-90 and 0-45 angle deposition. During the culture time here analyzed, the ALP levels started to increase after 7 days from the beginning of the differentiation and continued to increase until 28 days, which is in line with what can be found in literature for PCL scaffolds. ${ }^{[38,39]}$

To investigate the differences between the hMSCs residing in each pore geometry region within the gradient scaffold, a partition analysis was performed. After 14 days of culture, aggrecan, sox 9 , and collagen type II $\alpha$ presented a threefold induction in squared pores (0-90 design) and twofold increase in the 0-45 pattern with respect to the $0-30 / 0-15$ patterns. The trend was maintained after 28 days of differentiation at the biochemical level, since GAG/DNA amount was significantly higher in the squared pores compared to rhomboidal pores. An opposite trend was found in literature in studies correlating the behavior of chondrocytes in 3D plotted scaffolds displaying a pore-size gradient both at the genetic and biochemical levels, ${ }^{[40]}$ where genetic and biochemical markers increased with increasing the pore size. Similarly, Oh et al. showed an increase of chondrogenic markers expression such as sox- 9 and collagen type II $\alpha$ from small pores $(90-105 \mu \mathrm{m})$ to larger pores $(370-400 \mu \mathrm{m})$ in adipose derived stem cells. ${ }^{[41]}$ Our pore dimensions increased from the squared pore to the rhomboidal ones. The squared pore size is defined by the side, while each rhomboidal pore size is defined by the minor diagonal $(d)$, which did not vary significantly, and the major diagonal $(D)$, which varied greatly. Squared pores had a dimension of $560 \mu \mathrm{m} \pm 30 \mu \mathrm{m}$ in size, the $0-45$ plotting pattern generated pores with a $d$ of $500 \mu \mathrm{m}$ $\pm 40 \mu \mathrm{m}$ and a $D$ of $1350 \mu \mathrm{m} \pm 90 \mu \mathrm{m}$, whereas the $0-30$ and $0-15$ showed a $d$ of $540 \mu \mathrm{m} \pm 40 \mu \mathrm{m}$ and $470 \mu \mathrm{m} \pm 20 \mu \mathrm{m}$ and a $D$ of $1970 \mu \mathrm{m} \pm 80 \mu \mathrm{m}$ and $3010 \mu \mathrm{m} \pm 130 \mu \mathrm{m}$, respectively. The height of the pores remained constant at $140 \mu \mathrm{m} \pm 10 \mu \mathrm{m}$. In our scaffolds, the smallest pores were bigger than the larger pores of the Oh's study and the trend observed was opposite. The different range in pore size and the effect of the pore shape might explain this discrepancy. Several studies ${ }^{[21,42,43]}$ proved that the pore shape can influence ECM deposition, cellular cytoskeleton architecture, and speed of pore closure. In this study, both pore size and shape changed along the $z$-axis. GAGs are one of the major components of chondrocyte-deposited ECM. To distinguish between the influence of cellular density and scaffold architecture on GAGs formation, we normalized by DNA amount and by pore volume (Figure S7, Supporting Information), respectively. The pore size was included by normalizing the GAG amount by the cell density intended as DNA amount per volume unit. Results displayed the same trend with the same statistical significance, defining the pore shape as the main justification for the different behavior of hMSCs residing in the compartment of the $\mathrm{G}$ scaffolds.

An opposite trend was found for hMSCs osteogenic differentiation. At the genetic level a trend could be seen for bone sialoprotein, collagen type I, and osterix, suggesting an enhanced osteogenic differentiation in the rhomboidal pores compared to the squared ones. The results were confirmed by the biochemical analysis that showed an increased ALP activity in the rhomboidal 0-30/0-15 pore geometry when compared to the 0-45 rhomboidal or the $0-90$ squared pore geometry. In literature there are no studies, to the best of our knowledge, relating pore shape to hMSCs osteogenic differentiation that, in accordance to some studies, ${ }^{[9,44,45]}$ is not affected by the overall porosity of the construct. In this respect, the overall porosity of the gradient zones is the same, therefore it could be concluded that the differences present within the gradient scaffolds may be attributed to the variation in pore shape and size. In the case of ALP, we did not dissect the specific role of pore size by that of pore shape by normalizing for pore volume as we did for GAG deposition, because the ALP test measures the activity of the protein and not its production.

It was already proved that by supplementing the medium with soluble factors stimulating the osteogenic and chondrogenic hMSCs differentiation simultaneously, both lineages will be generated in culture. ${ }^{[46]}$ To further confirm the correlation between pore shape and the differences in hMSCs 
differentiation lineages, gradient scaffolds were seeded with hMSCs and cultured in a medium providing differentiation signal toward the osteogenic and the chondrogenic lineages. To do so, the osteogenic and chondrogenic medium were combined in a 1:1 ratio. The results further confirmed the findings of our previous tests. Rhomboidal pores displayed a significantly higher ALP activity, whereas the highest amount of GAGs was located in the squared pores. The effect of pore shape was confirmed with the normalization by cell density (Figure S7, Supporting Information).

A further possible explanation for the observed influence of pore shape gradients could be due to the local differences in oxygen availability to the cells. As in developmental biology it is known that in the presence of hypoxia chondrogenesis is facilitated, we reasoned that in these pore shape gradient scaffolds a change of pore shape could result in a change of local oxygen available, thus affecting the expression of hypoxia inducible factors. In particular, HIF- $1 \alpha$ and HIF- $2 \alpha$ were measured. Hypoxia-inducible factors, including HIF-1 $\alpha$ and HIF- $2 \alpha$, induce glycolysis and angiogenesis in order to try restoring oxygen homeostasis. Hypoxia-inducible expression of some genes, such as Glut-1, p53, p21, or Bcl-2, is dependent on HIF- $1 \alpha$ translocation to the cell nucleus. HIF- $2 \alpha$ regulates the vascular endothelial growth factor expression and its expression levels influence the relative contribution of aerobic and anaerobic cellular metabolism. Results showed, indeed, an increase of HIF- $1 \alpha$ and HIF- $2 \alpha$ with decreasing the pore rhomboidal geometry from $0^{\circ}-15^{\circ}$ to $0^{\circ}-90^{\circ}$ (Figure S8, Supporting Information), corresponding to the increased chondrogenesis observed by genetic and protein analysis.

The combination of the pore shape gradient in combination with predifferentiated cells in a preosteochondral construct may be considered as future perspective for the improved outcome of implants for osteochondral lesion treatment. According to our findings, gradient scaffolds should be implanted with the squared pores on the chondral side and the rhomboidal on the bone side. Further studies in animal models aiming at a better understanding if such behavior is maintained in vivo are needed. Additional research should be aimed at the analysis of the ECM composition in order to understand to which extent the construct mimics the anatomical and molecular transition from the subchondral bone to the chondral side in vivo. From a biofabrication perspective, it would be very interesting to show whether different pore size and shape gradients would result in a similar influence on stem cell activity in combination with soluble factors. In this respect, other AM technologies like stereolithography might be also considered, as this would allow expanding the geometrical features of the fabricated pore network. Melchels et al., for example, showed the creation of sinusoidal-like pore network patterns and how varying such network resulted in better cell seeding efficiency. ${ }^{[47]}$ The palette of biomaterials could be also expanded to determine if the observed effects are independent of the material chemistry or, more likely, can be further modulated by it.

In the past years, the microfracture technique was applied as surgical treatment of osteochondral lesions. ${ }^{[48]}$ Its application in combination with scaffolds displayed an enhanced healing of osteochondral defects. ${ }^{[49]}$ A possible study aiming at clinical translation, for example, could foresee the use of our gradient scaffolds in an orthotopic osteochondral defect with the squared pores facing the cartilage side and the rhomboidal ones facing the bone side, as previously suggested, where MSCs could be retrieved from the bone marrow through microfracture procedures. Practical examples where such scaffolds could be used in osteochondral locations comprise defects in long bone joints such as the knees, hips, and ankles, which are typically affected more frequently from traumatic accidents or ageing.

\section{Conclusion}

In this study a construct produced via additive manufacturing and presenting a gradient in pore shape was produced and its effect on hMSCs proliferation and differentiation was analyzed. A new fiber deposition pattern was presented, allowing the generation of pores of different shapes within the same construct. The 0-90 fiber alignment generated squared pores that supported enhanced differentiation of hMSCs toward the chondrogenic lineage, as shown by GAGs deposition and the expression of chondrogenic related genes. The variation in the fiber deposition pattern led to an increasing rhomboidal pore conformation by switching to $0-45,0-30$, and $0-15$ angle depositions. The most rhomboidal pore geometry sustained enhanced ALP activity and osteogenic related genes expression with respect to the other gradient zones. This trend was maintained when the gradient scaffold was cultured in a medium supporting both osteogenic and chondrogenic differentiation. The study confirmed that the pore shape can play a role as a modulator of cell differentiation in vitro.

\section{Experimental Section}

Scaffold Preparation: Scaffolds were fabricated via additive manufacturing with a Bioscaffolder (SysENG, Germany). Scaffolds made of PCL (Sigma-Aldrich, USA) were produced. Briefly the polymer was placed in a stainless syringe and processed at $100^{\circ} \mathrm{C}$. The application of 5 bars of pressure via a nitrogen flow from a pressurized cap drove the molten polymer through an extrusion screw rotating at $200 \mathrm{rpm}$.

During plotting, the needle diameter, layer thickness, fiber spacing, and speed were kept constant at $200 \mu \mathrm{m}, 150 \mu \mathrm{m}, 800 \mu \mathrm{m}$, and $180 \mathrm{~mm} \mathrm{~min}^{-1}$, respectively. The fiber deposition pattern was kept constant at 0-90 (NG 90) and 0-15 (NG 15) for the control scaffolds, while the gradient scaffold was plotted by varying the fiber deposition pattern every millimeter from $0-90$ to $0-45,0-30$, and $0-15$. The scaffolds were plotted as cylinders of $6 \mathrm{~mm}$ in diameter and $3.6 \mathrm{~mm}$ in height.

Mechanical Analysis: Compression tests were conducted using a rheometer (Discovery Hybrid Rheometer DHR-1, TA Instruments, US), which is equipped with a force rebalanced transducer for axial forces up to $50 \mathrm{~N}$ and sensitivity of $0.01 \mathrm{~N}$. Cylindrical specimens of about $4 \mathrm{~mm}$ in height were placed in between parallel metal plates of $25 \mathrm{~mm}$ in diameter. The vertical gap height and axial force were recorded at $37^{\circ} \mathrm{C}$ during controlled deformation speed experiments with $1 \mu \mathrm{m} \mathrm{s}^{-1}$ up to maximum forces of $1 \mathrm{~N}$ as well as $10 \mathrm{~N}$ and converted to an apparent compression strain. The unloading phase was also recorded with $1 \mathrm{\mu m} \mathrm{s}^{-1}$ in order to obtain information on the recovery behavior and possible hysteresis effects.

Cell Expansion and Culture: hMSCs (male, age 22) were retrieved from the Institute of Regenerative Medicine (Temple, Texas). Briefly, a bone marrow aspirate was drawn and mononuclear cells were separated using density centrifugation. The cells were plated to obtain adherent hMSCs, 
which were harvested when cells reached $60 \%-80 \%$ confluence. These were considered passage 0 (P0) cells. These P0 cells were expanded, harvested, and frozen at passage 1 (P1) for distribution. Cells were grown in MSC proliferation medium, which contains minimal essential medium $(\alpha$-MEM, Life Technologies, Bleiswijk, The Netherlands) supplemented

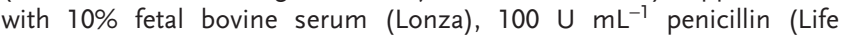
Technologies, Bleiswijk, The Netherlands), $10 \mu \mathrm{g} \mathrm{mL}^{-1}$ streptomycin (Life Technologies, Bleiswijk, The Netherlands), $2 \times 10^{-3} \mathrm{M}$ L-glutamine (Life Technologies, Bleiswijk, The Netherlands), $0.2 \times 10^{-3} \mathrm{M}$ L-ascorbic acid 2-phosphate magnesium salt (ASAp, Sigma-Aldrich, Zwijndrecht, The Netherlands), and $1 \mathrm{ng} \mathrm{mL} \mathrm{m}^{-1}$ of basic fibroblast growth factor-2 (bFGF-2, Fisher Scientific, Landsmeer, The Netherlands) at $37^{\circ} \mathrm{C}$ in a humid atmosphere with $5 \% \mathrm{CO}_{2}$. Cells were expanded up to $\approx 80 \%$ confluency and either frozen for further use or seeded on the scaffolds.

Cell Seeding on Scaffolds: Cells were seeded under static condition within the $\mathrm{G}$ and NG scaffolds. Briefly, after trypsinization with $0.25 \%$ trypsin (Life Technologies, Bleiswijk, The Netherlands), cells (passages 2-4) were counted using a Bückner chamber and re-suspended in proliferation medium at a density of 500000 cells in $40 \mu \mathrm{L}$. The day before seeding, scaffolds were disinfected in $70 \% \mathrm{EtOH}$ for $30 \mathrm{~min}$ under stirring, washed three times in phosphate buffered saline solution (PBS) (Lonza, Breda, The Netherlands), and incubated overnight in cell proliferation medium to allow protein adsorption on the scaffold's fibers. After protein adsorption, the $40 \mu \mathrm{L}$ of cell suspension was placed on the scaffold in a drop wise fashion to account for a cell seeding density of 500000 cells per scaffold. The seeded scaffolds were placed for $4 \mathrm{~h}$ in the incubator to allow cell adhesion before adding the cell culture medium.

Cells were cultured on the $G$ and NG scaffolds for $7 d$ in proliferation medium. At day 7 , the proliferation medium was changed and the cells within the scaffolds were cultured for another 28 days in basic medium, mineralization medium consisting of basic medium supplemented with $10 \times 10^{-9} \mathrm{M}$ dexamethasone (Sigma-Aldrich Zwijndrecht, The Netherlands) and $10 \times 10^{-3} \mathrm{M} \beta$-glycerol-phosphate (Sigma-Aldrich, Zwijndrecht, The Netherlands), and chondrogenic medium consisting of DMEM supplemented with $50 \mathrm{mg} \mathrm{mL}^{-1}$ ITS-premix (Becton Dickinson), $0.4 \times 10^{-3} \mathrm{M}$ Proline (Sigma-Aldrich, Zwijndrecht, The Netherlands), $50 \mathrm{mg} \mathrm{mL} \mathrm{m}^{-1}$ Ascorbic acid (ASAp, Sigma-Aldrich, Zwijndrecht, The Netherlands), $100 \mathrm{mg} \mathrm{mL} \mathrm{m}^{-1}$ sodium pyruvate (Sigma-Aldrich, Zwijndrecht, The Netherlands), $100 \mathrm{U} \mathrm{mL}^{-1}$ penicillin (Life Technologies, Bleiswijk, The Netherlands), $10 \mu \mathrm{g} \mathrm{mL}^{-1}$ streptomycin (Life Technologies, Bleiswijk, The Netherlands), $10 \mathrm{ng} \mathrm{mL}^{-1}$ transforming growth factor $\beta 3$ (TGF- $\beta 3$ ) (Life Technologies, Bleiswijk, The Netherlands), and $10^{-7} \mathrm{M}$ dexamethasone (Sigma-Aldrich, Zwijndrecht, The Netherlands). For the culture of the $G$ scaffolds under osteochondral conditions osteogenic and chondrogenic medium were mixed in a ratio 1:1 immediately prior the medium change. The medium was refreshed every 2 days.

Biochemical Assays: The cell number per scaffold was calculated from the $\mu \mathrm{g}$ of DNA, obtained by a Cyquant DNA assay kit (Life Technologies, Bleiswijk, The Netherlands). Briefly, each scaffold was cut to improve lysis efficiency and freeze-thawed five times. After the freeze-thawing process, cells within the scaffolds were lysated by diluting the 20x lysis buffer provided with the kit using a saline buffer $\left(180 \times 10^{-3} \mathrm{M} \mathrm{NaCl}\right.$, $1 \times 10^{-3} \mathrm{M}$ EDTA in distilled water). After $1 \mathrm{~h}$ of lysis, samples were sonicated two times for $10 \mathrm{~s}$ using a Branson sonifier 250 (Emerson Industrial Automation, USA). DNA content was quantified with a CyQuant kit (Life Technologies, Bleiswijk, The Netherlands) according to manufacturer's protocol and fluorescence was measured at $480 \mathrm{~nm}$ using a spectrophotometer LS50B (Perkin Elmer, The Netherlands). DNA concentrations were calculated from a $\lambda$ DNA standard curve.

To evaluate hMSCs differentiation toward the osteogenic lineage, ALP activity was measured using a CDP star kit (Roche, Almere, The Netherlands). For this purpose, $10 \mu \mathrm{L}$ of sample was added to a well of a white 96-well plate and $40 \mu \mathrm{L}$ of substrate was added. After $15 \mathrm{~min}$ incubation, luminescence was read using a spectrophotometer LS50B (Perkin Elmer, The Netherlands). ALP activity was corrected for DNA content.

To evaluate the differentiation toward the chondrogenic lineage, GAGs amount was quantified using 1,9-Dimethyl Methylene Blue (DMMB) assay. Specifically, $25 \mu \mathrm{L}$ of sample was placed into a transparent flat bottom 96 well plate and $5 \mu \mathrm{L}$ of $2.3 \mathrm{~m} \mathrm{NaCl}$ solution was added. Then, $150 \mu \mathrm{L}$ of DMMB solution was added and absorbance was read using a Multiscan Go (Fisher Scientific, Landsmeer, The Netherlands) plate reader at a wavelength of $525 \mathrm{~nm}$. GAGs content was quantified with a chondroitin standard curve and corrected for DNA content.

Osteocalcin (OCN) and collagen type-II hMSCs production was analysed after 14 days of culture using ELISA (human osteocalcin and collagen type II ELISA kits, Invitrogen). The test was performed on five samples per condition. In short, the medium was removed and samples were washed using ice cold PBS. A buffer was prepared using 890 volumes of miliQ water, 100 volumes of radio-immunoprecipitation assay (RIPA) buffer (Cell Technologies), and ten volumes of Halt protease and phosphatase inhibitor (Thermo Scientific). $150 \mu \mathrm{L}$ of the buffer was added to each sample and the samples were incubated on ice for $10 \mathrm{~min}$. The buffer was then collected from the samples and centrifuged at $11000 \mathrm{~g}$ for $15 \mathrm{~min}$. The supernatant was collected and used for the ELISA tests which were performed according to manufacturer's protocol. Briefly, $25 \mu \mathrm{L}$ of samples and standard solutions were added to the osteocalcin and collagen type II antibody-coated strip-well plates. $100 \mu \mathrm{L}$ of Anti-OST-HRP and $100 \mu \mathrm{L}$ of Anti-Col2-HRP conjugates, respectively, were added to each correspondent well, and the plates were covered and incubated for $2 \mathrm{~h}$ at room temperature. After incubation, the solutions in the wells were aspirated and the wells were washed three times using a washing solution provided in the kit. Then, $100 \mu \mathrm{L}$ of a chromogen solution (tetramethylbenzidine) was added to each well and the plates were incubated for $30 \mathrm{~min}$ at room temperature in the dark. Finally, $100 \mu \mathrm{L}$ of stop solution was added to each well. The optical density of each well was read at $450 \mathrm{~nm}$ using a plate reader (MULTISKAN GO, Thermo Scientific). A standard curve was plotted in Microsoft excel and concentration of OCN and collagen type II was determined in each well according to the standard curves.

Western Blot Analysis: hMSC passages 2-4 were cultured in normoxic (21\% oxygen) conditions on both petri dishes and AM scaffolds, and in hypoxic ( $2.5 \%$ oxygen) conditions on petri dishes only (positive control). The cells were lysed in RIPA lysis buffer (sc-24948, SantaCruz Biotechnology), and the protein content was determined using Pierce BCA protein assay kit (\#23227, Thermo Scientific Pierce), with bovine serum albumin as the standard. Each sample was mixed with $4 x$ Laemmli Sample Buffer (\#161-0737, BioRad) under denaturing conditions. $20 \mu \mathrm{g}$ of protein sample were loaded per lane and resolved on a $4 \%-20 \%$ precast polyacrylamide gel (\#456-8094, BioRad). Then, proteins were transferred to a polyvinylidene difluoride (PVDF) membrane for immunoblotting. After blocking $1 \mathrm{~h}$ at room temperature with $5 \%$ bovine serum albumine (BSA) in Tris-buffered saline containing 0.1\% Tween-20 (Santa Cruz Biotechnology), the membranes were incubated overnight at $4{ }^{\circ} \mathrm{C}$ with HIF-1 $\alpha$ (28b) antibody (\#sc-13515, Santa Cruz Biotechnology), or HIF-2 $\alpha$ antibody (\#sc-46691, Santa Cruz Biotechnology), diluted 1:250 in Tris-buffered saline containing 0.1\% Tween-20. GAPDH antibody (\#sc-365062, Santa Cruz Biotechnologies) diluted 1:2500 was used as loading control for normalization. Membranes were washed with Trisbuffered saline and incubated with horseradish peroxidase (HRP)conjugated secondary antibodies (DAKO) diluted 1:2500 in Tris-buffered saline containing $0.1 \%$ Tween-20 for $45 \mathrm{~min}$ at room temperature. After washing, blots were developed using Clarity Western ECL Substrate (\#1705060, BioRad) and the HRP activity of the blots was imaged using a BioRad Chemidoc Touch imager. Finally, blots were semi-quantified using Image).

Microscopy Analysis: G and NG scaffolds were analyzed by scanning electron microscopy (SEM, Philips - XL 30 ESEM-FEG). Directly after plotting, scaffolds were cut in half, gold sputtered, and analyzed. SEM images were analyzed using Image J software in order to measure the fiber diameter, fiber spacing, and pore dimensions.

Scaffolds cultured in basic medium for 28 days were fixed using $10 \%$ formalin, dehydrated by an increased series of ethanol concentration (50\%-60\%-70\%-80\%-90\%-96\%-100\%) and cut in half. The final dehydration step was carried out via immersion in Hexamethyldisilazane (Sigma-Aldrich, Zwijndrecht, The Netherlands) and overnight 
evaporation. Dry scaffolds were mounted on SEM stubs, gold sputtered (Cressington sputter coater 108 auto), and analyzed using $10 \mathrm{kV}$ and a working distance of $25 \mathrm{~mm}$.

Gene Expression Analysis: For gene expression analysis, the scaffolds were taken from the medium, washed twice with PBS, cut into small pieces, placed in an Eppendorf tube containing $750 \mu \mathrm{L}$ of TRIzol (Invitrogen), and stored at $-80{ }^{\circ} \mathrm{C}$. In the case of partition analysis the gradient scaffolds were cut in order to separate the gradient zones and the three samples were located in the same vial prior to the addition of TRIzol, in order to ensure the collection of enough RNA. RNA isolation was performed by using a Bioke RNA II nucleospin RNA isolation kit (Macherey-Nagel). $150 \mu \mathrm{L}$ of $\mathrm{CHCl}_{3}$ was added and the vials were vigorously mixed, followed by a centrifugation at $12000 \mathrm{~g}$ for $15 \mathrm{~min}$ at $4{ }^{\circ} \mathrm{C}$. The aqueous phase was transferred into a new tube and an equal amount of $70 \%$ ethanol was added. The mixture was transferred into a filter column from the kit and the extraction was carried on by following the manufacturer's protocol. RNA concentration and purity was evaluated via an ND1000 spectrophotometer (Nanodrop Technologies, USA); cDNA was synthetized using iScript (BIO-RAD) according to the manufacturer's protocol. Quantitative polymerase chain reaction was performed on the obtained cDNA by using the iQ SYBR Green Supermix (BIO-RAD) and the primers listed in Table S1 (Supporting Information). PCR reaction was carried out on the MyiQ2 Two-Color Real-Time PCR Detection System (BIO-RAD) under the following conditions: the CDNA was denatured for $10 \mathrm{~min}$ at $95^{\circ} \mathrm{C}$, followed by 45 cycles, consisting of $15 \mathrm{~s}$ at $95{ }^{\circ} \mathrm{C}, 15 \mathrm{~s}$ at $60^{\circ} \mathrm{C}$, and $15 \mathrm{~s}$ at $72{ }^{\circ} \mathrm{C}$. A melting curve was generated from each reaction to test the presence of primer dimers and a specific product. The cycle threshold was calculated by the Bio-Rad iQ5 optical system software, in which the threshold was set in the lower log-linear region of the fluorescent signal. $C_{t}$ values were normalized by the B2M housekeeping gene and $\Delta C_{t}$ ((average of $C_{t}$ control)- $C_{t}$ value). Results were expressed as fold induction in mRNA expression normalized to the gene expression of the gradient scaffolds cultured in basic medium. In the partition analysis, the relative RNA expression was normalized by the squared pore region $(0-90)$ for the osteogenic analysis and the rhomboidal region $(0-30 / 15)$ for the chondrogenic analysis.

Statistical Analysis: All the quantitative data are expressed as mean \pm standard deviation. Statistics were performed using IBM SPSS Statistics 20. A two-way ANOVA with Tukey as post hoc test was used. Statistical significance between the control group and the experimental group is indicated with $(*)$ which represents a $p$-value $<0.05$, (***) which represents a $p$-value $<0.01$, and ( $(* * *)$ which represents a $p$-value $<0.001$

\section{Supporting Information}

Supporting Information is available from the Wiley Online Library or from the author.

\section{Acknowledgements}

This research was financially supported by the Technology Foundation STW (STW, 11135) and by the Province of Limburg. The experimental support of $\mathrm{N}$. Leone in mechanical testing is greatly appreciated.

Received: January 25, 2016 Published online: April 24, 2016

[1] R. Langer, J. P. Vacanti, Science 1993, 260, 920.

[2] B. M. Abdallah, M. Kassem, Gene Ther. 2008, 15, 109.

[3] F. P. W. Melchels, M. A. N. Domingos, T. J. Klein, J. Malda, J. P. Bartolo, D. W. Hutmacher, Prog. Polym. Sci. 2012, 37, 1079.
[4] W. L. Grayson, F. Zhao, B. Bunnell, T. Ma, Biochem. Biophys. Res. Commun. 2007, 358, 948.

[5] S. H. Hsu, C. T. Chen, Y. H. Wei, Stem Cells 2013, 31, 2779.

[6] A. J. Engler, S. Sen, H. L. Sweeney, D. E. Discher, Cell 2006, 126, 677.

[7] S. Even-Ram, V. Artym, K. M. Yamada, Cell 2006, 126, 645.

[8] T. Kawano, M. Sato, H. Yabu, M. Shimomura, Biomater. Sci. 2014, 2, 52.

[9] P. Kasten, I. Beyen, P. Niemeyer, R. Luginbuhl, M. Bohner, W. Richter, Acta Biomater. 2008, 4, 1904.

[10] T. B. Woodfield, J. Malda, J. de Wijn, F. Peters, J. Riesle, C. A. van Blitterswijk, Biomaterials 2004, 25, 4149.

[11] L. D. Harris, B.-S. Kim, D. J. Mooney, J. Biomed. Mater. Res. 1998, 42, 402.

[12] D. W. Hutmacher, Biomaterials 2000, 21, 2529.

[13] C. E. de Andrea, P. C. Hogendoorn, J. Pathol. 2012, 226, 219.

[14] A. Di Luca, C. A. van Blitterswijk, L. Moroni, Birth Defects Res., Part C 2015, 105, 34.

[15] K. Lavery, P. Swain, D. Falb, M. H. Alaoui-Ismaili, J. Biol. Chem. 2008, 283, 20948.

[16] C. R. Nuttelman, M. C. Tripodi, K. S. Anseth, J. Biomed. Mater. Res. A 2006, 76, 183.

[17] F. Barry, R. E. Boynton, B. Liu, J. M. Murphy, Exp. Cell Res. 2001, 268, 189.

[18] C. Phornphutkul, K.-Y. Wu, P. A. Gruppuso, Mol. Cell. Endocrinol. 2006, 249, 107

[19] I. Martin, S. Miot, A. Barbero, M. Jakob, D. J. Wendt, J. Biomech. 2007, 40, 65

[20] D. Schaefer, I. Martin, P. Shastri, R. F. Padera, R. Langer, L. E. Freed, G. Vunjak-Novakovic, Biomaterials 2000, 21, 2599.

[21] C. M. Bidan, K. P. Kommareddy, M. Rumpler, P. Kollmannsberger, P. Fratzl, J. W. Dunlop, Adv. Healthcare Mater. 2013, 2, 186.

[22] A. Berner, M. A. Woodruff, C. X. Lam, M. T. Arafat, S. Saifzadeh, R. Steck, J. Ren, M. Nerlich, A. K. Ekaputra, I. Gibson, D. W. Hutmacher, Int. J. Oral. Maxillofac. Surg. 2014, 43, 506.

[23] T. B. F. Woodfield, C. A. van Blitterswijk, J. de Wijn, T. J. Sims, A. P. Hollander, J. Riesle, Tissue Eng. 2005, 11, 1297.

[24] J. Genzer, J. Adhesion 2005, 81, 417.

[25] J. Genzer, Annu. Rev. Mater. Res. 2012, 42, 435.

[26] A. M. Greiner, M. Jackel, A. C. Scheiwe, D. R. Stamow, T. J. Autenrieth, J. Lahann, C. M. Franz, M. Bastmeyer, Biomaterials 2014, 35, 611.

[27] T. M. Keenan, A. Folch, Lab Chip 2008, 8, 34

[28] C. H. Kuo, J. Xian, J. D. Brenton, K. Franze, E. Sivaniah, Adv. Mater. 2012, 24, 6059

[29] S. H. Oh, T. H. Kim, J. H. Lee, Biomaterials 2011, 32, 8254.

[30] M. Singh, N. Dormer, J. R. Salash, J. M. Christian, D. S. Moore, C. Berkland, M. S. Detamore, J. Biomed. Mater. Res. A 2010, 94, 870.

[31] J. M. Sobral, S. G. Caridade, R. A. Sousa, J. F. Mano, R. L. Reis, Acta Biomater. 2011, 7, 1009.

[32] D. W. Hutmacher, T. Schantz, I. Zein, K. W. Ng, S. H. Teoh, K. C. Tan, J. Biomed. Mater. Res. 2001, 55, 203.

[33] M. A. Woodruff, D. W. Hutmacher, Prog. Polym. Sci. 2010, 35, 1217.

[34] J. T. Schantz, T. C. Lim, C. Ning, S. H. Teoh, K. C. Tan, S. C. Wang, D. W. Hutmacher, Neurosurgery 2006, 58, ONS-E176.

[35] X. Wang, E. Wenk, X. Zhang, L. Meinel, G. Vunjak-Novakovic, D. L. Kaplan, J. Controlled Release 2009, 134, 81.

[36] J. R. Tse, A. J. Engler, PLoS ONE 2011, 6, e15978.

[37] P. Yilgor, R. A. Sousa, R. L. Reis, N. Hasirci, V. Hasirci, Macromol. Symp. 2008, 269, 92

[38] H. A. Declercq, T. Desmet, E. E. Berneel, P. Dubruel, M. J. Cornelissen, Acta Biomater. 2013, 9, 7699.

[39] S. A. Park, S. H. Lee, W. D. Kim, Bioprocess. Biosyst. Eng. 2011, 34, 505. 
[40] G. I. Im, J.-Y. Ko, J. H. Lee, Cell Transplant. 2012, 21, 2397.

[41] S. H. Oh, T. H. Kim, G. I. Im, J. H. Lee, Biomacromolecules 2010, 11, 1948.

[42] P. Joly, G. N. Duda, M. Schone, P. B. Welzel, U. Freudenberg, C. Werner, A. Petersen, PLoS ONE 2013, 8, e73545.

[43] J. Knychala, N. Bouropoulos, C. J. Catt, O. L. Katsamenis, C. P. Please, B. G. Sengers, Ann. Biomed. Eng. 2013, 41, 917.

[44] M. E. Gomes, H. L. Holtorf, R. L. Reis, A. G. Mikos, Tissue Eng. 2006, 12, 801 .
[45] V. Karageorgiou, D. Kaplan, Biomaterials 2005, 26, 5474.

[46] J. Li, S. Mareddy, D. M. Tan, R. Crawford, X. Long, X. Miao, Y. Xiao, Tissue Eng. Part A 2009, 15, 2481.

[47] F. P. Melchels, B. Tonnarelli, A. L. Olivares, I. Martin, D. Lacroix, J. Feijen, D. J. Wendt, D. W. Grijpma, Biomaterials 2011, 32, 2878.

[48] J. R. Steadman, W. G. Rodkey, J. J. Rodrigo, Clin. Orthop. Relat. Res. 2001, 391, S362.

[49] H. A. Breinan, S. D. Martin, H. P. Hsu, M. Spector, J. Orthop. Res. 2000, 18, 781 